\title{
O ENSINO BILIINGUE EM NATAL/RN: UM MAPEAMENTO PRELIMINAR DO CONTEXTO
}

\section{BILINGUAL EDUCATION IN NATAL/RN: A PRELIMINARY ACCOUNT OF THE CONTEXT}

\author{
Orlando Vian $\mathrm{Jr}^{* 1}$ \\ Janaina Weissheimer ${ }^{* 2}$ \\ Lígia Leite ${ }^{* 3}$ \\ Rodrigo Queiroz ${ }^{* 4}$ \\ Wilka Soares ${ }^{* 5}$ \\ José Mauro Uchôa ${ }^{*}$ \\ James Vasconcelos ${ }^{* 7}$
}

RESUMO: Este texto objetiva traçar um mapa preliminar do ensino bilíngue em Natal/RN com base nos conceitos de sujeito bilíngue (GROSJEAN, 1982; WEI, 2000) e de educação bilíngue (HAMERS; BLANC, 2000; FISHMAN; LOVAS, 1970; DALE; TANNER, 2012). Os dados foram gerados através de questionários e entrevistas em quatro escolas particulares da região urbana da cidade. Os resultados indicam que a maioria das escolas aplica o bilinguismo parcial

\footnotetext{
UFRN, Natal, Professor Adjunto III, E-mail: orlando.ufrn@gmail.com

2 UFRN, Natal, Professora Adjunta III, E-mail: janaina.weissheimer@ gmail.com

3 UFRN/PPgEL, Natal, Mestre em Estudos da Linguagem, E-mail: ligiasleite@yahoo.com.br

4 UFRN/PPgEL, Natal, Mestre em Estudos da Linguagem, E-mail: rodrigoqrz1@gmail.com

5 UFRN/PPgEL, Natal, Mestre em Estudos da Linguagem, E-mail: wilka1308@gmail.com

6 UFRN/PPgEL, Natal, Doutorando em Estudos da Linguagem, E-mail:maurouchoa@hotmail.com

7 UFRN/PPgEL, Natal, Mestre em Estudos da Linguagem, E-mail: jamesvasconcelos@gmail.com
} 
biletrado, com diferenças em relação à carga horária dedicada a cada uma das línguas.

PALAVRAS-CHAVE: Bilinguismo. Educação bilíngue. Natal/RN.

ABSTRACT: This paper aims at presenting a preliminary account of the bilingual education in Natal/RN based on the notions of bilingual (GROSJEAN, 1982; WEI, 2000) and bilingual education (HAMERS; BLANC, 2000; FISHMAN; LOVAS, 1970; DALE; TANNER, 2012). The data were collected through questionnaires and interviews in four private bilingual schools in Natal/RN. Results indicate that most of the schools include two languages concomitantly in their bilingual curriculum with differences as regards the hour load to work with each of the languages.

KEYWORDS: Bilingualism. Bilingual education. Natal/RN. 


\section{O ENSINO BILÍNGUE EM NATAL/RN: UM MAPEAMENTO PRELIMINAR DO CONTEXTO}

\section{INTRODUÇÃO}

Estamos inseridos em um contexto no qual as barreiras linguísticas já não são mais tão aparentes. Ao se falar em inovação, o acesso à informação é cada vez maior, assim como a competitividade e, por essa razão, no mundo do trabalho, profissionais procuram melhorar seus currículos como forma de se manter competitivos no mercado. As crianças, consequentemente, são mais cobradas em relação ao seu futuro e, em virtude disso, do ponto de vista da formação em relação ao conhecimento de línguas adicionais, ser bilíngue hoje pode ser não apenas um sinal de status social, mas também pode abrir inúmeras perspectivas pessoais e profissionais no atual contexto sócio-histórico-cultural. Além disso, devido ao contato tão frequente com as tecnologias da internet e com os meios de comunicação em geral, torna-se cada vez mais raro identificar alguém que não tenha tido contato ou utilizado uma palavra ou expressão estrangeira, mesmo que sem perceber tal uso.

Essa tendência levou ao surgimento de novas escolas bilíngues no contexto brasileiro e à adoção de currículos ditos bilíngues, fenômeno já apontado por Marcelino (2009), aumentando, por conseguinte, o interesse em 
relação à educação bilíngue no ensino fundamental, uma vez que esse tipo de ensino tem sido inserido cada vez mais cedo na vida dos estudantes em alguns contextos urbanos.

Em função desse panorama, o bilinguismo tem sido objeto de investigação de um crescente número de linguistas no mundo (GROSJEAN, 1982; BIALYSTOK, 2001; GARCIA, 2009) dentre outros e, nos últimos anos, no Brasil (MARCELINO, 2009; ZIMMER; FINGER; SCHERER, 2008; MEGALE, 2005, 2012; LEITE, 2013) dentre outros, os quais tentam entender as várias facetas desse fenômeno e suas relações com os contextos mais amplos, como o campo educacional ou profissional.

Tendo esse cenário como pano de fundo, o presente estudo foi conduzido com o objetivo de traçar um mapa preliminar do ensino bilíngue na cidade de Natal/RN, em função tanto do surgimento de escolas bilíngues na cidade quanto da adoção, por escolas de ensino fundamental, de currículos bilíngues. Nosso objetivo visa não somente a tomar conhecimento do contexto sócio-histórico-cultural em que nos inserimos, mas também, com base nas informações obtidas, a empreender outras ações relacionadas ao ensino bilíngue propriamente dito e à formação de professores que atuem nesses contextos.

O estudo tomou por base as seguintes perguntas: (1) De que maneira a educação bilíngue se configura nas escolas particulares de Natal/RN que oferecem programas específicos para educação bilíngue?, e (2) Como estão organizados os atores (escola, organização didática e pedagógica, alunos etc.) dentro das concepções para o ensino bilíngue na realidade atual de escolas particulares da cidade de Natal/RN?

Apresentamos, primeiramente, o aporte teórico que embasa o estudo, mais especificamente as noções de sujeito bilíngue e de educação bilíngue. Em seguida, é descrita a metodologia que guiou a condução do estudo ${ }^{1}$ para, na sequência, expormos os resultados obtidos e discuti-los à luz da teoria, seguindo-se as considerações finais.

1 Os dados aqui apresentados são resultantes de coletas realizadas em maio de 2011 pelos colaboradores deste texto e participantes da disciplina Introdução ao Bilinguismo, minitrada por Vian Jr. e por Weissheimer no Programa de Pós-graduação em Estudos da Linguagem (PPgEL) da Universidade Federal do Rio Grande do Norte (UFRN). 


\section{SUJEITO BILÍNGUE E EDUCAÇÃO BILÍNGUE}

Como nosso objetivo é conhecer as práticas bilíngues na cidade de Natal/ $\mathrm{RN}$, dois pontos de partida são necessários: definir como concebemos "sujeito bilíngue", assim como o que se entende por "educação bilíngue”, perfazendo um percurso teórico à luz de pesquisadores basilares em estudos sobre o ensino e a aprendizagem de línguas estrangeiras no campo do bilinguismo.

A partir desse mapeamento, poderá ser estabelecida de maneira concreta a situação do tratamento apresentado pelas escolas acerca do ensino bilíngue. Além disso, será produzida uma amostragem panorâmica dos aspectos que envolvem professores, coordenação da escola bilíngue, programa adotado para o ensino e alunos.

\subsection{Definição de sujeito bilíngue}

Definir "sujeito bilíngue", além de ser uma tarefa complexa, em virtude das diferentes perspectivas pelas quais se pode observar o fenômeno, depende também da maneira como se concebe a língua. Por essa razão, as concepções vêm mudando constantemente, não apenas devido à época, mas também no que concerne à abordagem teórica, uma vez que os estudos acompanham os diversos aspectos envolvidos no fenômeno do bilinguismo, como ensino de línguas, psicologia, neurociências, biologia, sociologia, pedagogia e tantas outras áreas que permeiam a noção de bilinguismo e pelas quais o conceito circula.

Associam-se a isso, ainda, novas condições sócio-históricas e novas práticas em que as interações primam por sua multilingualidade e multiculturalidade. Em meio a essa realidade, pode-se, inicialmente, conceber o sujeito bilíngue como um indivíduo que expressa esse estado de coisas em termos de adequação, adaptação e classificação.

Em seu estudo seminal em língua portuguesa sobre sujeito bilíngue, Mello (1999) apresenta diversas concepções que foram se alternando com o passar do tempo e com o avanço dos estudos linguísticos e que tiveram impacto nas definições. Dentre essas concepções, pode ser citada a de Bloomfield (1933), por exemplo, que define o sujeito bilíngue como alguém 
que tem o desempenho linguístico semelhante ao de um nativo em todos os níveis, incluindo fala, compreensão, leitura e escrita. Haugen (1953), também de acordo com Mello (1999), afirma que os bilíngues teriam uma escala gradativa de fluência. Eles produziriam enunciados significativos mínimos até atingirem um nível máximo de fluência. Outros estudiosos, como Mackey (1972) e Grosjean (1982), definem o bilinguismo como a alternância de uma ou mais línguas, simplesmente.

Em função dessa evolução histórica, foram surgindo diferentes conceitos e distintas categorizações dos tipos de sujeitos bilíngues, tais como aquelas apresentadas por Wei (2000), que apresenta uma lista extensa com diversas classificações, conforme discutido por pesquisadores brasileiros como Cavalcanti (1999), Cristino (2007), Marcelino (2009), Flory e Souza (2009), Megale $(2005,2012)$, dentre outros.

A partir de tais pesquisas, será adotada neste texto a definição de sujeito bilíngue conforme preceituado por Wei (2000), para nos referirmos aos indivíduos que se comunicam em duas línguas. Contudo, deve-se incluir entre esses indivíduos aqueles com diferentes graus de proficiência nessas línguas e que muitas vezes fazem uso de três, quatro ou mais línguas.

Nossa opção pela acepção preceituada por Wei (2000) deve-se ao fato de, pela nossa prática profissional e contato com professores e sujeitos bilíngues, percebermos as inúmeras variáveis que entram em ação quando a língua é usada por indivíduos bilíngues, não ficando circunscrita apenas ao desempenho semelhante ao de um nativo, como preceituava Bloomfield (1933) no início do século. Novas tendências e pesquisas em neurociências revelam que essa concepção não se restringe apenas ao cognitivo ou ao desempenho linguístico, mas a outros elementos que compõem o complexo fenômeno do bilinguismo e contribuem para a definição de sujeito bilíngue e, consequentemente, têm impacto na educação bilíngue.

\subsection{Definição de educação bilíngue}

Em relação à educação bilíngue, adotamos a definição proposta por Hamers e Blanc (2000: 321), como sendo "qualquer sistema de educação escolar no qual, em dado momento e período, simultânea ou conse- 
cutivamente, a instrução é planejada e ministrada em pelo menos duas línguas"2.

Esses autores (HAMERS; BLANC, 2000: 322), com base na proposta de Fishman e Lovas (1970), apresentam uma classificação para a educação bilíngue a partir de quatro categorias que variam quanto:

(i) à intensidade com que a língua é trabalhada;

(ii) aos tipos de programas de imersão;

(iii) ao objetivo da língua no ensino;

(iv) ao status da língua-alvo para a comunidade.

No tocante à intensidade, a língua pode ser trabalhada de diferentes maneiras, alternando, dessa forma, os programas bilíngues, dos quais emergem o bilinguismo transicional, em que a língua materna é usada como veículo facilitador da língua-alvo; o bilinguismo monoletrado, quando a escola usa as duas línguas, mas a criança é alfabetizada apenas na segunda; o bilinguismo parcial biletrado, em que ambas as línguas são utilizadas, mas a língua materna é utilizada para as matérias mais culturais; e o bilinguismo total biletrado, no qual todas as atividades são desenvolvidas nas duas línguas.

Sobre os programas do tipo imersão, Hamers e Blanc (2000) os dividem em três tipos: Imersão Inicial Total, em que toda instrução antes da educação fundamental é dada na língua estrangeira e na língua materna, sendo que esta é iniciada gradativamente até que o tempo das duas seja equivalente; Imersão Inicial Parcial, em que as duas línguas são utilizadas desde o início da vida escolar; e Imersão Tardia, em que a instrução na língua estrangeira é feita a partir do ensino médio.

Quanto ao objetivo, o programa de educação bilíngue pode ser classificado em "compensatório", em que primeiramente existe a instrução na língua materna para uma maior integração ao contexto da escola; de "enriquecimento", em que ambas as línguas são utilizadas como meios de instrução de conteúdos e desenvolvidas desde a alfabetização; e, por último, de "ma-

2 Tradução nossa do original em inglês: "any system of school education in which, at a given moment in time and for a varying amount of time, simultaneously or consecutively, instruction is planned and given in at least two languages". 
nutenção do grupo", em que a língua e a cultura do grupo minoritário são preservadas e aprimoradas.

A categoria status da língua varia de acordo com o modo como a língua é utilizada na comunidade, como, por exemplo, se tem importância primária ou secundária na educação, se é a língua de casa ou a língua da escola, se é a língua mais importante no mundo em detrimento da menos importante ou menos valorizada e, por fim, se é a língua institucionalizada ou não na comunidade.

De uma forma distinta, Dale e Tanner (2012) especificam três diferentes abordagens para o ensino bilíngue. Segundo os autores, existe o ensino de língua baseado em conteúdos (content-based language teaching), no qual o conteúdo das diferentes matérias é ensinado em aulas de segunda língua. Há, também, o ensino integrado de conteúdo e língua (content and language integrated learning), em que conteúdos são ensinados ao mesmo tempo em que a segunda língua é ensinada, mas nas aulas dos respectivos conteúdos. Há, ainda, a imersão (immersion), em que os conteúdos são ensinados na segunda língua, mas não há preocupação com o ensino desta língua em si, como, por exemplo, no caso das escolas internacionais. De acordo com os autores, essas três abordagens representam um contínuo, no qual, em um extremo, teríamos um explícito e intenso foco no ensino da segunda língua (content-based language teaching) e, em outro, nenhuma (ou quase nenhuma) preocupação com o ensino da segunda língua per se (immersion).

No contexto brasileiro, ainda, temos que levar em conta as prescrições do Ministério da Educação. Vale ressaltar que a Secretaria Estadual de Educação do Rio Grande do Norte e a Secretaria Municipal de Educação da cidade de Natal pouco mencionam ou possuem documentos norteadores sobre diretrizes a respeito de noções sobre educação bilíngue, seja estabelecendo quantidade de horas/aula, seja especificando quais conteúdos devem ser abordados pelas escolas. O Ministério da Educação trata, em linhas gerais, de sua consolidação no Brasil e da importância de um segundo idioma no contexto atual da sociedade, dando ênfase a métodos de ensino (em muitos casos por meio de franquias terceirizadas que atuam dentro das escolas regulares privadas) que levam em consideração o ensino de conteúdos das áreas de conhecimento (como Matemática, Ciências, História, Geografia 
etc.) de forma lúdica e no idioma-alvo, fazendo com que o foco não seja apenas o aprendizado da língua em si, e sim um aprendizado com significado e contextualizado.

\section{METODOLOGIA DE PESQUISA}

Este estudo adota uma metodologia qualiquantitativa para o tratamento dos dados coletados juntos às escolas bilíngues em Natal/RN. Por se tratar de uma pesquisa preliminar e exploratória, essa primeira etapa teve por objetivo (i) mapear as escolas que se nomeiam bilíngues ou que preceituam adotar o ensino bilíngue em seu currículo, respondendo à nossa primeira pergunta de pesquisa sobre como se configura a educação bilíngue nas escolas particulares do contexto, bem como, a partir daí, (ii) traçar o perfil dos professores em tais escolas, dos materiais utilizados e, principalmente, das concepções de bilinguismo subjacentes às suas propostas pedagógicas, como subsídios para responder à segunda pergunta em relação ao modo como estão organizados os atores nesse cenário.

Como instrumentos para geração de dados foram utilizados questionários para estabelecimento dos perfis das escolas e de seus professores, assim como entrevistas com os coordenadores pedagógicos de cada um dos estabelecimentos de ensino (ver Anexo).

Os dados foram coletados em quatro escolas da região urbana da cidade de Natal, situada no estado do Rio Grande do Norte. Essas instituições de ensino selecionadas para compor o corpus do mapeamento apresentam aspectos em torno do escopo de ensino bilíngue e difundem um ensino com configuração diferenciada das escolas regulares. As escolas mapeadas nesta pesquisa oferecem ensino pago e a sua clientela faz parte de uma pequena parcela da sociedade, geralmente com um maior poder aquisitivo. Os pais dos alunos dessas escolas, em sua maioria, desejam incluir seus filhos em um ensino diferenciado e, de modo geral, com uma configuração nova de educação em relação a outras escolas particulares de Natal.

Os alunos-pesquisadores participantes do curso Introdução ao Bilinguismo realizaram as entrevistas com os coordenadores pedagógicos das quatro 
escolas, as quais foram gravadas em áudio com o consentimento dos entrevistados, sendo as respostas transcritas posteriormente.

Para geração dos dados em relação aos aspectos da educação bilíngue, foram realizadas entrevistas estruturadas com perguntas sobre o ensino bilíngue em si e sobre a escola e seus professores (ver Anexo), as quais, posteriormente, foram reorganizadas em três macroestratos:

(1) o perfil da escola;

(2) o perfil dos professores;

(3) a proposta pedagógica.

Com base nos dados obtidos por meio dos questionários e das entrevistas, analisamos e discutimos os resultados no próximo item.

\section{RESULTADOS E DISCUSSÃO}

Este estudo foi conduzido com o intuito de mapear a configuração da educação bilíngue nas escolas particulares de Natal/RN que oferecem programas específicos para educação bilíngue e de verificar como estão organizados os atores (escola, organização didática e pedagógica, alunos etc.) dentro das concepções para o ensino bilíngue na realidade atual dessas escolas. Nesta seção, apresentamos os resultados da coleta de dados e os discutimos à luz das teorias apresentadas na fundamentação teórica.

De modo a preservar a identidade das escolas, atribuímos a elas os nomes fictícios de Escola A, Escola B, Escola C e Escola D. Os dados são analisados a partir das seguintes categorias determinadas a priori: o perfil das escolas, o perfil dos professores e a proposta pedagógica de cada uma delas.

\subsection{0 perfil das escolas bilíngues}

Em primeiro lugar, nesta categoria, analisamos o tempo de existência da cada uma das escolas na cidade e a relação entre o tempo de existência da escola e do programa bilíngue oferecido por ela. 
No Gráfico 1 apresentamos o tempo de existência das escolas, sendo que o eixo vertical representa a medida em anos e o eixo horizontal traz as letras usadas para representar as escolas pesquisadas.

12

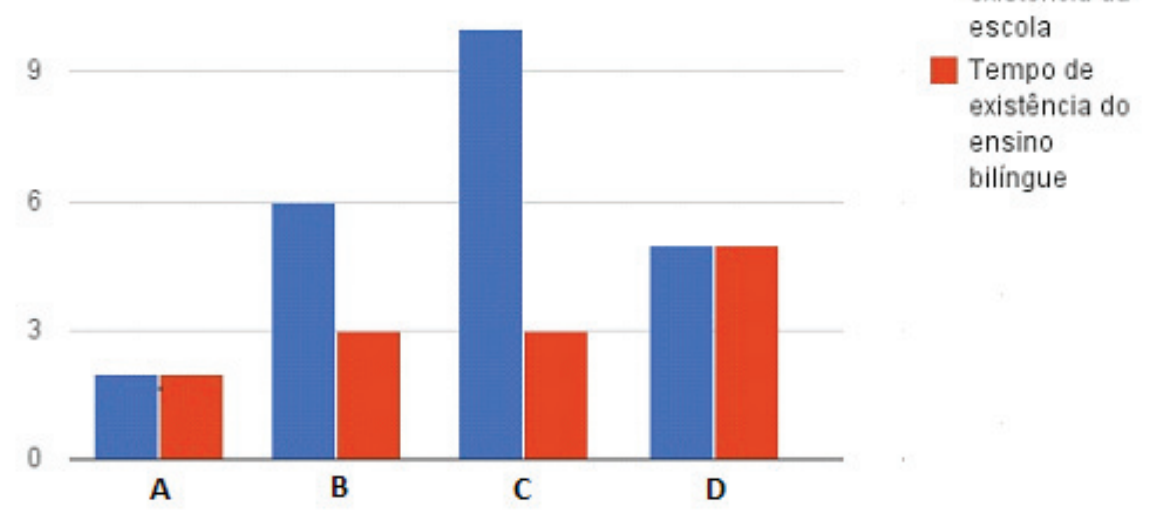

Tempo de

existência da escola

Tempo de existência do ensino bilingue

\section{Gráfico 1 - Tempo de existência da escola e do ensino bilíngue}

De acordo com o Gráfico 1, pode-se observar que duas das quatro escolas (Escola A e Escola D) foram inauguradas já oferecendo ensino bilíngue. A Escola A existe desde 2009 e a Escola D desde 2006. As Escolas B e C existem desde 2005 e 2001, respectivamente; no entanto, ambas só começaram a oferecer ensino bilíngue em 2008. Conforme esses dados, podemos perceber que o ensino bilíngue em Natal é relativamente recente, se levarmos em consideração o ano 2011, período em que ocorreu a coleta de dados, sendo que a escola que oferece tal serviço por mais tempo atuava com essa modalidade havia apenas cinco anos.

Em seguida, investigamos a carga horária destinada à língua materna e à segunda língua em cada uma das escolas visitadas a partir dos dados apresentados no Gráfico 2. 


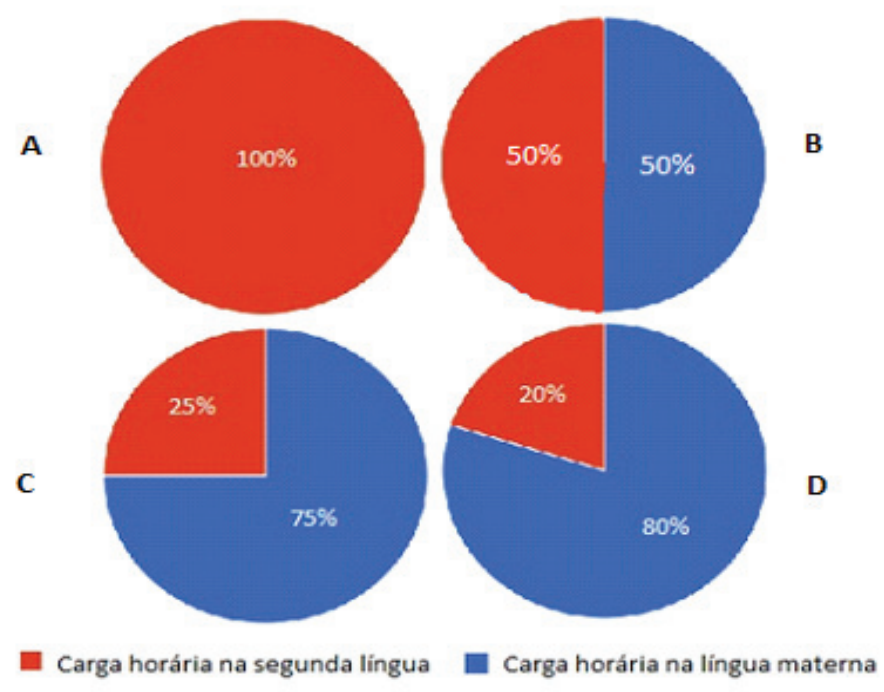

Gráfico 2 - Carga horária na língua materna (português) e na segunda língua (inglês)

Conforme evidenciado no Gráfico 2, a Escola A é a única que oferece ensino 100\% na segunda língua, com uma carga horária de quatro horas diárias (tendo a opção de tempo integral, que passa para oito horas diárias). Já as Escolas B, C e D têm parte do ensino na segunda língua e parte na língua materna, sendo que a porcentagem de carga horária destinada à segunda língua varia de $20 \%$ a $50 \%$. Na Escola B, só existe ensino integral, com carga horária diária de oito horas, sendo metade ministrada na segunda língua e metade na língua materna. Na Escola C, assim como na Escola D, apenas uma hora da carga horária diária é dedicada à segunda língua, sendo que a Escola C possui quatro horas de ensino e a Escola D oferece cinco horas. Portanto, a primeira tem $25 \%$ e a segunda $20 \%$ da carga horária diária na segunda língua.

Quanto à intensidade de contato e exposição à segunda língua, levando-se em consideração as classificações propostas por Fishman e Lovas (1970) e Harmes e Blanc (2000), poderíamos dizer que a Escola B oferece um ensino bilíngue do tipo Imersão Inicial Total, uma vez que toda instrução na educação fundamental é dada na segunda língua. Já a Escola A, segundo a classificação de Harmes e Blanc (2000), realiza um ensino bilíngue do tipo 
Imersão Inicial Parcial, já que as duas línguas são utilizadas desde o início da vida escolar. Por último, o ensino bilíngue proposto pelas Escolas C e D seria, segundo a proposta de Fishman e Lovas (1970), o parcial biletrado, em que ambas as línguas são utilizadas, mas a língua materna é utilizada em maior quantidade, em termos de porcentagem de exposição.

Uma terceira preocupação em relação ao estabelecimento de um perfil das escolas bilíngues foi quanto ao número de alunos em cada uma das escolas e, principalmente, no que tange ao número de alunos em cada turma bilíngue, pois, em se tratando da aquisição de uma segunda língua, sabe-se que essa é uma variável essencial, uma vez que a quantidade de alunos por turma é geralmente apontada como inversamente proporcional ao grau de proficiência que os alunos atingem, principalmente na habilidade oral.

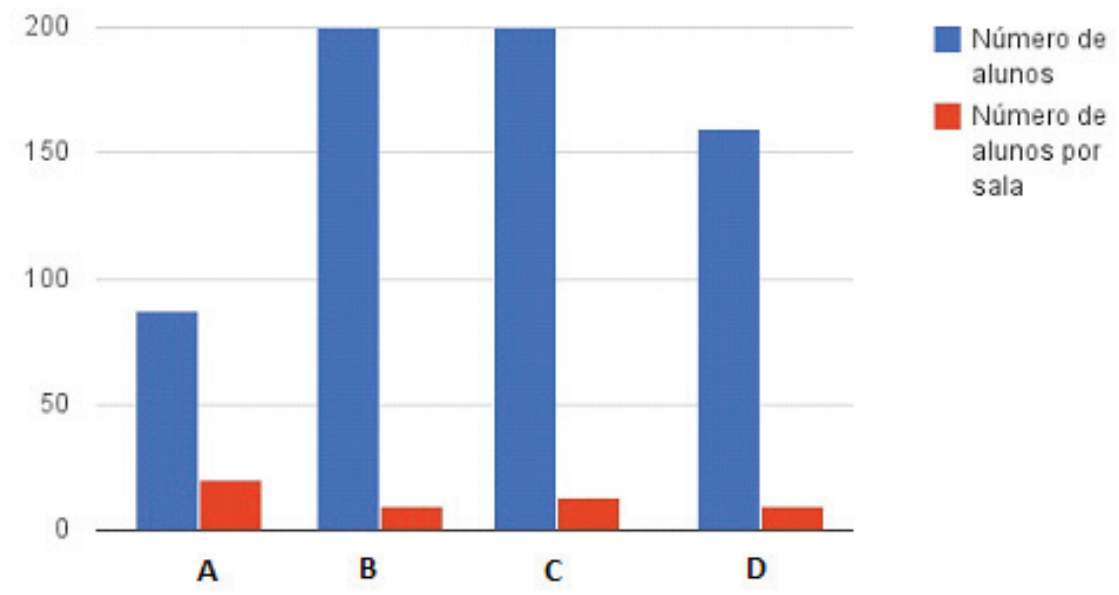

Gráfico 3 - Número de alunos nas escolas e em cada turma do ensino bilíngue

O Gráfico 3 mostra que a Escola A possui 87 alunos com uma média de 15 e um máximo de 20 alunos por sala. A Escola D tem 200 alunos com no máximo 10 alunos por sala. Na Escola B, estão matriculados 160 alunos, com uma média de 7 a 13 alunos por sala. Na Escola C estudam mais de 200 alunos, com um mínimo de 7 e máximo de 13 por sala. Embora não se possa precisar qual a quantidade ideal de alunos por turma em um ambiente 
bilíngue, estudos apontam para um máximo de 15 alunos como o número propício ao desenvolvimento das habilidades linguísticas em uma segunda língua. Pode-se observar que as quatro escolas analisadas parecem atender a esse quesito, com exceção da Escola A, que chega a possuir turmas com até 20 alunos.

A próxima seção deste artigo é destinada a traçar o perfil dos professores responsáveis pelo ensino bilíngue nas escolas pesquisadas.

\subsection{0 perfil dos professores bilíngues}

O primeiro objetivo aqui é analisar a relação entre o número de professores falantes de inglês como segunda língua e o número de professores falantes nativos de inglês em cada escola bilíngue pesquisada.

\section{2}

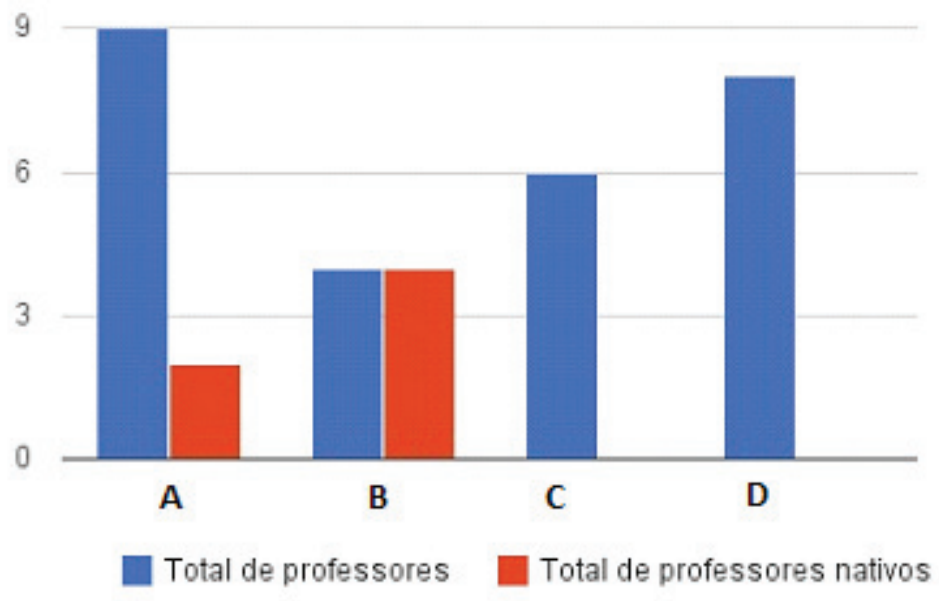

Gráfico 4 - Número de professores nativos e não nativos de inglês em cada escola

De acordo com os dados apresentados no Gráfico 4, podemos observar um panorama distinto entre as escolas em relação à língua nativa de seus professores do currículo bilíngue. A Escola B é a única que conta apenas 
com professores nativos do inglês, perfazendo um total de quatro professores de língua inglesa. Além disso, nessa mesma escola, os quatro professores já tiveram experiência com o ensino bilíngue no exterior: alguns no Canadá, outros na Nova Zelândia, na Inglaterra e nos Estados Unidos. A Escola A possui nove professores de língua inglesa, sendo dois deles nativos. Entre os nove professores dessa escola, três deles têm experiência no exterior. A Escola D tem oito professores de inglês no currículo bilíngue e a Escola $\mathrm{C}$ possui seis, sendo que nenhuma das duas possui professores nativos em língua inglesa. Dos oito professores de inglês da Escola D, quatro têm experiência no exterior e todos os seis professores da Escola $C$ possuem experiência no exterior.

No que diz respeito à experiência prévia que os professores das escolas pesquisadas tinham com o ensino bilíngue antes de integrarem o quadro das escolas pesquisadas (informação apresentada no Gráfico 5), a média reside em cerca de cinco anos de experiência no momento da coleta de dados. No caso da Escola C, nenhum professor tinha tido experiência com bilinguismo em nenhuma outra escola antes de iniciar sua atuação na escola pesquisada, por essa razão ela não figura no Gráfico 5. Esse fato evidencia que não só o ensino bilíngue em Natal em si é relativamente recente, como citado anteriormente, mas também a experiência dos professores locais com essa modalidade de ensino. Em virtude disso, acredita-se que os cursos de graduação em Letras e Pedagogia que formam os profissionais para atuarem nessas escolas não tenham ainda incorporado, em suas grades curriculares, alternativas teóricas e metodológicas que visem a preparar os professores em formação especificamente para essa atividade. Como já discutido, esse é um dos objetivos da realização desse mapeamento, ou seja, a necessidade de se entender a demanda local pelo ensino bilíngue para que, a partir daí, possamos traçar propostas de mudança em nível acadêmico. 


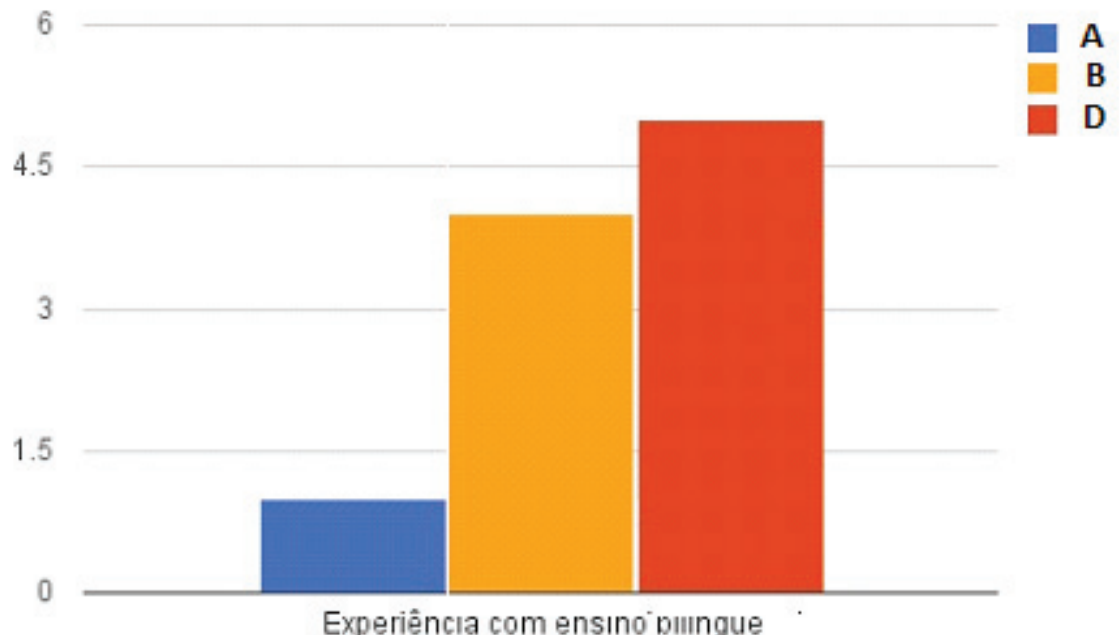

Experiêncıa com ensıno oııngue

Gráfico 5 - Experiência dos professores com o ensino bilíngue

Em relação à capacitação que os professores das escolas bilíngues analisadas recebem, o Quadro 1 evidencia diferentes práticas que vão desde o incentivo para a participação em congressos e eventos da área até treinamento com equipe estrangeira. No entanto, a modalidade mais comum de capacitação são as reuniões pedagógicas que variam entre semanais (Escola A), três vezes ao ano (Escola B e Escola C) ou semestrais (Escola D).

Quadro 1: Capacitação dos professores bilíngues nas escolas pesquisadas

\begin{tabular}{|c|c|c|c|}
\hline Escola A & Escola B & Escola C & Escola D \\
\hline $\begin{array}{l}\text { - Reuniões semanais } \\
\text { - Treinamento com } \\
\text { equipe estrangeira } \\
\text { - Incentivo à partici- } \\
\text { pação no BRAZ-TE- } \\
\text { SOL } \\
\text { - Programa na in- } \\
\text { ternet }\end{array}$ & $\begin{array}{l}\text { - Orientação de } \\
\text { um departamento } \\
\text { - Workshop três } \\
\text { vezes ao ano com } \\
\text { professores e equi- } \\
\text { pe pedagógica }\end{array}$ & $\begin{array}{l}\text { - Cursos duas ou } \\
\text { três vezes ao ano }\end{array}$ & $\begin{array}{l}\text { - Orientações } \\
\text { - Reciclagens se- } \\
\text { mestrais }\end{array}$ \\
\hline
\end{tabular}

A necessidade de um constante aperfeiçoamento e reflexão por parte dos professores bilíngues que venham a ser proporcionados pela escola onde 
atuam faz-se evidente para nós à medida que, como já pontuamos, esses profissionais provavelmente não tiveram qualquer discussão em seus cursos de graduação sobre teorias e metodologias específicas para o ensino e/ou aprendizagem bilíngues. É fundamental, portanto, que as escolas propiciem e/ou incentivem a constante reciclagem e reflexão nesse sentido.

Na seção a seguir, analisamos a proposta pedagógica desenvolvida por cada uma das escolas bilíngues integrantes do corpus desta pesquisa.

\subsection{A proposta pedagógica adotada pelas escolas bilíngues}

Em primeiro lugar, é importante identificar qual a concepção de bilinguismo e de ensino bilíngue que cada escola apresenta. Para isso, as análises desta seção serão ilustradas com trechos das entrevistas realizadas com os coordenadores pedagógicos das referidas escolas.

Quanto ao que é bilinguismo, podemos observar que as Escolas A e D salientam principalmente o aspecto comunicativo, ou seja, a habilidade de comunicar-se efetivamente nas duas línguas:

Bilinguismo representa a habilidade de poder compreender, escutar, ler e reproduzir e expressar espontaneamente as suas ideias nas duas línguas. A palavra-chave seria espontaneamente (Coordenadora da Escola A).

A escola acredita que o bilíngue é aquele que se comunica nas duas línguas, tanto na forma escrita quanto oralmente. Também são levados em conta fatores sociais e culturais - valores relevantes para cada idade (Coordenadora da Escola D).

Essa perspectiva nos leva a entender que há uma ênfase na aprendizagem da segunda língua no ensino bilíngue dessas escolas, e não nos conteúdos veiculados a partir dela. Segundo Dale e Tanner (2012), essa proposta se aproxima do ensino de língua baseado em conteúdos (content-based language teaching), em que o conteúdo das diferentes matérias é ensinado em aulas 
de segunda língua e o foco no desenvolvimento das habilidades linguísticas é primordial. Essa abordagem se assemelha ao ensino que acontece, por exemplo, em institutos de idiomas.

No caso da Escola B, percebemos uma orientação mais ampla no sentido da concepção do bilinguismo e do ensino bilíngue que extrapola os limites linguísticos, contemplando aspectos culturais e de acesso a diversas esferas do conhecimento:

A concepção da escola é que esse ensino não seja somente um fato mecânico, ou que se aprenda o inglês porque é a mais falada no mundo, mas sim que possa abrir a possibilidade para o mundo dos negócios e também servir de acesso a vários tipos de informação. É ainda mais aberto e global que possa possibilitar o acesso a outros tipos de cultura, como na literatura, música, artes plásticas. Não é somente uma escola que trabalha com conteúdos em inglês, mas que produza um conhecimento de mundo, em que se possa fazer várias atividades em inglês, pois é uma maneira de aproximar o conhecimento sobre a cultura de outros países (Coordenador da Escola B).

Essa visão se aproxima mais, de acordo com Dale e Tanner (2012), do ensino integrado de conteúdo e língua (content and language integrated learning), em que conteúdos são ensinados ao mesmo tempo em que a segunda língua é ensinada, mas nas aulas dos respectivos conteúdos.

Ainda quanto à concepção de sujeito bilíngue, percebe-se na visão da coordenadora pedagógica da Escola C uma orientação mais "tradicional" do que é ser bilíngue. Essa compreensão aproxima-se da concepção clássica de Bloomfield (1933), que define o sujeito bilíngue como alguém que tem o desempenho linguístico semelhante ao de um nativo em todos os níveis, incluindo produção e compreensão oral (speaking, listening) e produção e compreensão escrita (writing, reading): 
O sujeito bilíngue é alguém capaz de entender e falar a sua língua materna e uma segunda língua com o mesmo grau de desenvoltura de um falante nativo (Coordenadora da Escola C).

Tal visão da coordenadora surpreende, de certa forma, uma vez que concepções contemporâneas sobre o sujeito bilíngue geralmente não mais consideram o nível de proficiência nativo como um modelo a ser seguido ou um alvo a ser atingido. Perspectivas como a adotada pelos autores deste artigo, em consonância com o que propõe Wei (2000), por exemplo, entendem o sujeito bilíngue de uma forma mais flexível, como alguém que simplesmente alterna uma ou mais línguas e o faz com diferentes graus de proficiência nessas línguas e diferentes níveis de comando nas quatro habilidades de cada língua, dependendo dos contextos em que se insere, de seus interlocutores e das necessidades comunicativas.

Quanto à relação entre a língua materna e a segunda língua no processo de ensino e de aprendizagem bilíngues, percebe-se, no trecho da entrevista destacado a seguir, que a Escola D concebe o bilinguismo de forma transicional, como postulado por Fishman e Lovas (1970), em que a língua materna é usada como veículo facilitador para a língua-alvo:

A criança lida com o que ela já estudou em português, o inglês entra com um papel de familiarizar o que elas já viram em português, a língua estrangeira fica na retaguarda aguardando um retorno aos temas já vistos. Não é ensinado o que elas não viram no ensino regular (Coordenadora da Escola D).

Por fim, no que tange ao material didático adotado pelas escolas bilíngues, percebemos que três das quatro escolas pesquisadas possuem materiais desenvolvidos por franquias especificamente para o ensino bilíngue. Entre essas três escolas, duas utilizam materiais didáticos elaborados por franquias nacionais (Escolas D e C) e uma escola utiliza material de franquia estrangeira, baseado no currículo de uma escola estrangeira (Escola 
A). Apenas na Escola B são os próprios professores que elaboram o material didático utilizado no ensino bilíngue. Especulamos que o fato de a Escola B não adotar material previamente elaborado por franquias pode estar associado ao relativamente alto índice de experiência com o ensino bilíngue por parte dos professores dessa escola (se comparado com as demais), como reportado anteriormente, bem como ao fato de seu programa bilíngue ter sido instituído simultaneamente à própria escola, o que sugere que esta foi concebida desde o início para um propósito bilíngue.

$\mathrm{Na}$ última parte deste artigo, esboçamos algumas considerações acerca das discussões aqui propostas e apontamos possíveis limitações deste estudo, juntamente com sugestões para investigações futuras.

\section{CONSIDERAÇÕES FINAIS}

A partir das visitas às instituições bilíngues no contexto estudado, observamos, inicialmente, que as escolas e suas respectivas coordenações responsáveis pela inclusão do ensino bilíngue acreditam ser essa uma forma de criar um vínculo concreto com o mundo globalizado, e que assim seja possível formar um sujeito bilíngue que não encontre barreiras ao se expressar na sua comunicação cotidiana, seja na estrutura da língua, seja nas relações socioculturais e profissionais com o outro. Nesse processo, metodologias, métodos e demais aspectos do ensino, como conteúdos trabalhados, carga horária e materiais didáticos utilizados, aparentemente passam a ter um papel "secundário", sendo mais importante a ideia de ensino globalizado voltado para uma estrutura macro que possa vir a "gerar" no aluno um aprendizado mais fixo, maneira lúdica e diversificada de atividades e projetos, como geralmente são concebidas as atividades desenvolvidas da infância.

Considerando a natureza do ensino bilíngue oferecido pelas escolas pesquisadas, enquanto, por um lado, observa-se que a maioria das escolas aplica o bilinguismo parcial biletrado (com exposição simultânea às duas línguas, no caso, português e inglês), por outro, verifica-se que há diferenças em relação à carga horária dedicada a cada uma das línguas nas diferentes escolas.

Quanto às práticas pedagógicas, a comunicação efetiva na língua-alvo - 
no caso, o inglês - parece ser o foco de todos os envolvidos na pesquisa, de maneira que venha a ser produzida da forma mais espontânea possível, não limitando os alunos a sentenças predeterminadas ou descontextualizadas. Observa-se, ainda, na fala dos coordenadores, que a língua materna desempenha uma função de suporte e ponto de partida, facilitando gradativamente a aquisição da língua-alvo.

Este estudo visou a apresentar um mapeamento preliminar das práticas pedagógicas realizadas por quatro escolas bilíngues na cidade de Natal/RN, não tendo a pretensão de esgotar o tema ou oferecer um panorama definitivo de tais práticas. Acreditamos que os dados aqui apresentados podem auxiliar no conhecimento do contexto sócio-histórico-cultural em que estamos inseridos, bem como na implementação de outras ações relacionadas ao ensino bilíngue propriamente dito e à formação de professores que atuam nesses contextos.

Futuras pesquisas em bilinguismo podem dedicar-se a atualizar os dados aqui reportados, uma vez que o ensino bilíngue no Brasil encontra-se em franca expansão. Ainda, podem comparar a realidade aqui relatada com outras regiões do país, principalmente pela constante necessidade do uso da língua inglesa no mundo globalizado, além da troca de informação trazida pela internet e da inovação tecnológica que se presencia em nosso país, sendo o bilinguismo um elemento essencial para a integração local-global. 


\section{ANEXO}

ROTEIRO DE ENTREVISTA

I NOME DA ESCOLA BILÍNGUE:

II PESSOA ENTREVISTADA:

III CARGO:

IV FORMAÇÃO:

V PERFIL DA ESCOLA BILÍNGUE:

a) Há quanto tempo a escola existe?

b) Há quanto tempo a escola oferece ensino bilíngue?

c) Quais ciclos ou anos da educação básica a escola possui?

d) Qual a frequência ou carga horária semanal?

e) Qual o número de alunos da escola?

f) Quantos alunos por sala?

g) Quantos alunos possuem pais nativos?

h) O ensino bilíngue é opcional ou obrigatório?

i) Como é composta a equipe pedagógica?

j) Quantos professores?

VI PERFIL DO PROFESSOR BILÍNGUE:

a) Qual a formação dos professores?

b) Quantos professores nativos ou não nativos atuam na escola?

c) Quantos professores já tiveram experiência no exterior?

d) Qual o tempo de exposição dos professores à língua-alvo? (proficiência)

e) Quanto tempo de experiência com o ensino bilíngue os professores possuem?

f) Os professores são, de alguma forma, orientados e capacitados pela escola para atuar no ensino bilíngue?

VII PROPOSTA PEDAGÓGICA:

a) Qual a concepção da escola sobre o bilinguismo?

b) Qual a concepção da escola sobre o ensino bilíngue? 
c) Qual a proposta pedagógica da escola para o ensino bilíngue?

d) Com que frequência os professores se reúnem com a equipe pedagógica da escola?

e) Qual o material didático utilizado? Como se caracteriza?

f) Como é a prática dos professores em sala de aula?

g) Como é acompanhado o desenvolvimento dos alunos?

h) Quais habilidades linguísticas são trabalhadas em sala de aula?

i) Existe alguma política de divulgação sobre o ensino bilíngue? (website, panfletos, reuniões com pais etc.).

j) Qual a participação dos pais (conversas informais com os professores, com a equipe pedagógica) sobre a proposta de ensino bilíngue da escola?

\section{REFERÊNCIAS BIBLIOGRÁFICAS}

BIALYSTOK, Ellen. Bilingualism in development: language, literacy and cognition. Cambridge: Cambridge University Press, 2001.

BLOOMFIELD, Leonard. Language. New York: Henry Holt, 1933.

CAVALCANTI, Marilda. Estudos sobre a educação bilíngue e escolarização em contextos de minorias linguísticas no Brasil. In: Revista D.E.L.T.A., v. 15, n. especial, p. 385-417, 1999.

CRISTINO, Luciana dos Santos. Bilinguismo e code-switching: um estudo de caso. Dissertação Mestrado (Linguística Aplicada e Estudos da Linguagem). Pontifícia Universidade Católica de São Paulo, São Paulo, 2007.

DALE, Liz; TANNER, Rosie. CLIL Activities: a resource for subject and language teachers. Cambridge: Cambridge University Press, 2012.

FISHMAN, Joshua Aaron; LOVAS, John. Bilingual education in a sociolinguistic perspective. In: TESOL Quarterly, v. 4, p. 215-22, 1970. 
FLORY, Elizabete Villibor; SOUZA, Maria Thereza Costa Coelho. Bilinguismo: diferentes definições, diversas implicações. In: Revista Intercâmbio, São Paulo, v. 19, p. 23-40, 2009.

GARCIA, Ofelia. Bilingual education in the 21st century: a global perspective. Malden: Wiley-Blackwell, 2009.

GROSJEAN, François. Life with two languages: an introduction to bilingualism. Cambridge: Harvard University Press, 1982.

HAMERS, Josiane F.; BLANC, Michel. Bilinguality and bilingualism. Cambridge: Cambridge University Press, 2000.

HAUGEN, Einar. The Norwegian Language in America: a study in bilingual behavior. Philadelphia: University of Pennsylvania Press, 1953.

LEITE, Lígia. O desenvolvimento da interlíngua na aprendizagem da escrita em inglês em uma escola bilíngue: um estudo exploratório. Dissertação (Mestrado em Linguística Aplicada e Estudos da Linguagem) - Universidade Federal do Rio Grande do Norte, Natal, 2013.

MACKEY, William Francis. Bilingual education and a binational school. Rowley: Newbury House, 1972

MARCELINO, Marcello. Bilinguismo no Brasil: significado e expectativas. In: Revista Intercâmbio, São Paulo, v. 19, p. 1-22, 2009.

MEGALE, Antonieta Heyden. Bilinguismo e educação bilíngue: discutindo conceitos. In: Revista Virtual de Estudos da Linguagem - ReVEL, v. 3, n. 5 , agosto de 2005 .

MEGALE, Antonieta Heyden. Eu sou, eu era, não sou mais: um relato de sujeitos fal(t)antes em suas vidas entre línguas. Dissertação (Mestrado em 
Linguística Aplicada e Estudos da Linguagem). Pontifícia Universidade Católica de São Paulo, São Paulo, 2012.

MELLO, Heloísa Augusta Brito. O falar bilíngue. Goiânia: Editora da UFG, 1999.

WEI, Li. Dimensions of bilingualism. In: WEI, Li. The bilingualism reader. London; New York: Routledge, 2000. 541 p.

ZIMMER, Márcia; FINGER, Ingrid; SCHERER, Lilian. Do bilinguismo ao multilinguismo: interseções entre a psicolinguística e a neurolinguística. In: Revista Virtual de Estudos da Linguagem - ReVEL, v. 6, n. 11, ago. 2008. 
